Check for updates

Cite this: J. Anal. At. Spectrom., 2021, 36,954

Received 19th December 2020 Accepted 18th March 2021

DOI: 10.1039/d0ja00518e

rsc.li/jaas

\section{Determination of the naturally occurring vanadium-complex amavadin in Amanita muscaria with HPLC-ICPMS $†$}

\begin{abstract}
Simone Braeuer, (D) $\ddagger^{*}$ Martin Walenta, (D) Lorenz Steiner (D) and Walter Goessler (D)
Amanita muscaria, also known as the fly agaric mushroom, can accumulate vanadium (V), with up to several hundred $\mathrm{mg} \mathrm{V} \mathrm{kg}^{-1}$ dry mass. It is long known that $\mathrm{V}$ is present in $A$. muscaria as a complex called amavadin, but methods for the investigation of the distribution and biosynthesis of amavadin in mushrooms are missing. Here, we describe the development of the first sensitive method for the determination of amavadin and other $\mathrm{V}$-containing compounds in environmental samples by employing high performance liquid chromatography (HPLC) and inductively coupled plasma mass spectrometry (ICPMS). A strong anion-exchange column serves as the stationary phase, and the mobile phase consists of an aqueous ammonium citrate buffer and ethylenediaminetetraacetate (EDTA). The concentration and $\mathrm{pH}$ of the mobile phase as well as the column temperature were evaluated to optimize the separation. With the final method, amavadin is eluted in less than 17 minutes, and its limit of detection is $0.05 \mu \mathrm{g} \mathrm{L}^{-1}$. Moreover, the compound's two isomers are separated from each other and can be quantified independently. The method was applied to extracts of fruit-body samples of A. muscaria. The extraction efficiency was $74 \pm 12 \%$, and amavadin accounted for $75-96 \%$ of the extracted $V$. In addition, significant concentrations of other $V$ species could be detected, which have never been described before. Our results demonstrate that $V$ speciation in mushrooms is more complex than assumed until now and that more in-depth investigations on this matter are needed. The developed method enables the investigation of organic and inorganic $\vee$ species in the environment, even at low concentrations.
\end{abstract}

\section{Introduction}

Institute of Chemistry, University of Graz, Universitaetsplatz 1, $8010 \mathrm{Graz}$, Austria. E-mail: simone.braeuer@uni-graz.at; Tel: +43316 3805318

$\dagger$ Electronic supplementary information (ESI) available. See DOI: 10.1039/d0ja00518e

\$ Current address: Atomic \& Mass Spectrometry Research Unit, Department of Chemistry, Ghent University, Krijgslaan 281-S12, 9000 Ghent, Belgium.

\subsection{Vanadium}

Vanadium (V) is widely distributed in nature, being the $22^{\text {nd }}$ most abundant element in the earth's crust. ${ }^{1}$ The essentiality of $\mathrm{V}$ has been proven for some bacteria, terrestrial fungi, lichens

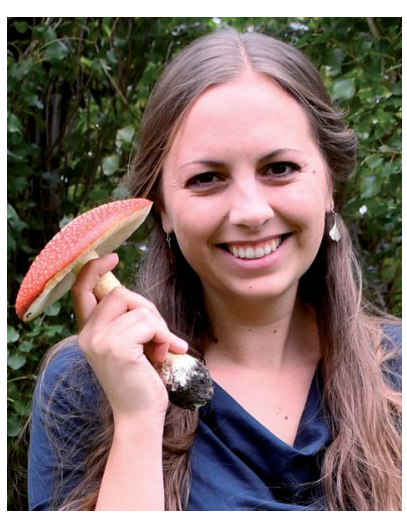

Simone Braeuer obtained her PhD in 2018 from the University of Graz, Austria, in the research group of Prof. Walter Goessler. She stayed there for one more year and then started a Postdoctoral fellowship at Ghent University, Belgium, in the Atomic \& Mass Spectrometry research group of Prof. Frank Vanhaecke. Her work in Graz focused on the development and application of ICPMS and HPLC-ICPMS methods for the determination of trace element species in the environmental context. For her PhD, her main focus was on arsenic in mushrooms. Since mushrooms also contain other elements, sometimes in surprising concentrations and species, she soon became interested in some of those as well. The fascination with ICPMS and mushrooms grew so big that she is still investigating mushrooms in her current Postdoctoral project, but now also via multi-collector ICPMS and laser ablation ICPMS. She thinks that multidisciplinary and international collaborations are both fascinating and essential for environmental research. She also believes that high-quality, state-of-the-art analytical chemistry is of key importance - for environmental as well as for many other (interdisciplinary) studies. 
and marine macro-algae ${ }^{2}$ but for other living organisms, the role of $\mathrm{V}$ is still unclear. ${ }^{3}$ Because of the similarity of vanadate and phosphate, it has been suggested that $\mathrm{V}$ could play a role in the regulation of the phosphate metabolism. A variety of $\mathrm{V}$ compounds are under investigation as potential anti-diabetic drugs $^{4}$ and for several other medical applications. ${ }^{5}$ On the other hand, $\mathrm{V}$ can also be toxic to living organisms. ${ }^{6,7}$ It is usually thought that vanadate, the inorganic pentavalent form of $\mathrm{V}$, is more toxic than $\mathrm{V}$ in the oxidation state +4 and that organic $\mathrm{V}$ species are less toxic than inorganic ones. ${ }^{8}$ However, the adverse health effects of $\mathrm{V}$ exposure are usually only observed in laboratory animals and people working in the $\mathrm{V}$ processing industry, ${ }^{3}$ with a few exceptions. ${ }^{9}$

Ascidians (sea squirts) and some fan worms can accumulate incredible amounts of $\mathrm{V}$. The highest concentrations, up to $350 \mathrm{mM}$ (more than $17000 \mathrm{mg} \mathrm{V} \mathrm{kg}{ }^{-1}$ ), have been reported in Ascidia gemmata, ${ }^{\mathbf{1 0}}$ where specialized cells store the element in its otherwise rather unstable trivalent form. ${ }^{11}$ Until now, the actual function of $\mathrm{V}$ in ascidians remains elusive. ${ }^{\mathbf{1 0 , 1 2}}$

\subsection{Amanita muscaria}

Another living organism that accumulates $\mathrm{V}$ is the macrofungus Amanita muscaria (L.) Lam, also prominently known as fly agaric, along with a few closely related species. While most other mushrooms typically contain less than $0.5 \mathrm{mg} \mathrm{V} \mathrm{kg}^{-1}$ dry mass (dm), ${ }^{13-15}$ A. muscaria can easily take up more than 100 $\mathrm{mg} \mathrm{V} \mathrm{kg}{ }^{-1} \mathrm{dm}^{\mathbf{1 3 , 1 6 - 1 8}}$

The highest concentrations, namely up to $1000 \mathrm{mg} \mathrm{V} \mathrm{kg}{ }^{-1}$ $\mathrm{dm}$, have been found in the "bulb", which is the lowest part of the stipe. ${ }^{17,19,20}$ This part of the fruit body is prone to contamination by soil, and no measures to minimize such contamination were described in the respective studies. However, the $\mathrm{V}$ concentrations in European top soils are reportedly between 1.28 and $537 \mathrm{mg} \mathrm{kg}^{-1}$, with a median of only $60 \mathrm{mg} \mathrm{kg}^{-1} .{ }^{9}$ This makes it unlikely that $1000 \mathrm{mg} \mathrm{V} \mathrm{kg}^{-1}$ in a mushroom sample are solely to be attributed to remaining soil particles.

Concerning the other parts of the fruit body, the $\mathrm{V}$ concentrations in the stipe, cap skin and cap flesh were at least two times lower than in the corresponding bulb sample, while they were again a little higher in the gills (but still lower than in the bulb; the concentrations were only shown in a rough graph, so that no exact numbers can be cited). ${ }^{19}$ In the spores, only 1-5 $\mathrm{mg} \mathrm{V} \mathrm{kg}{ }^{-1} \mathrm{dm}$ were detected. ${ }^{19}$ Many other macrofungal species have been investigated for their $\mathrm{V}$ concentrations, including several members of the genus Amanita, but only A. regalis and $A$. velatipes accumulated as much $\mathrm{V}$ as $A$. muscaria. $^{17,21}$

\subsection{Amavadin}

In 1972, Bayer and Kneifel found that V is present in A. muscaria as a negatively charged compound ( $\mathrm{pH}$ 1-10), which they named "Amavadin". ${ }^{22}$ They reported a tentative sum formula for the compound, and electron paramagnetic resonance (EPR) spectroscopy indicated that the oxidation state of $\mathrm{V}$ was +4 . One year later, they published a first structure of the complex. ${ }^{23}$ Further structural investigations by EPR, infrared (IR), and other techniques followed, which have been reviewed a few times over the decades. ${ }^{24-26}$ EPR spectra suggested that the different parts of the fruit body contained the same compound. ${ }^{2027}$ The first synthesis of amavadin was reported in $1986,{ }^{28}$ and in the following years, a new structure of the complex was proposed ${ }^{29}$ and confirmed by crystallography, X-ray absorption spectroscopy and nuclear magnetic resonance (NMR) spectroscopy. ${ }^{\mathbf{3 4 , 3 5}}$

Amavadin, as shown in Fig. 1, contains a rather unusual nonoxo $\mathrm{V}(\mathrm{Iv})$ ion (the vanadyl ion $\mathrm{VO}^{2+}$ is more common) and can exist in two isomers, namely $\Delta$-amavadin and $\Lambda$-amavadin. The two tetradentate ligands can coordinate to the $\mathrm{V}$ center in two distinct orientations, as shown in Fig. 1. It was reported that synthetic and also natural amavadin were present in solution in an almost equal mixture of the $\Delta$ - and $\Lambda$-isomers, although it was noted that isomerization could theoretically occur after extracting or dissolving the compound. ${ }^{30,31}$ The first enantioselective synthesis of amavadin was carried out by Hubregtse et al., who found that the ratio of the diastereoisomers $\Lambda: \Delta$ was first 2.27, but later decreases to 0.8 at equilibrium. ${ }^{32,33}$

Because of the reversible oxidation of $\mathrm{V}(\mathrm{Iv})$ to $\mathrm{V}(\mathrm{v})$ in amavadin, several studies investigated its catalytic properties. It was found that a broad range of reactions can be catalyzed by the complex. This led to the synthesis and investigation of amavadin analogues with a different metal ion in the center or slightly modified ligands. ${ }^{35}$

The biological role of amavadin is unknown. A few proposals have been made, but none have been proven so far. It has been speculated that amavadin was part of an ancient, primitive enzyme, which has been outdated through evolution. ${ }^{26}$ Other suggestions are that it serves as a protective agent against external microbial pathogens or aids the self-regeneration of damaged fruit-body tissue by cross-linking thiol groups in proteins. $^{32,34}$ The ability to mediate water oxidation gave the
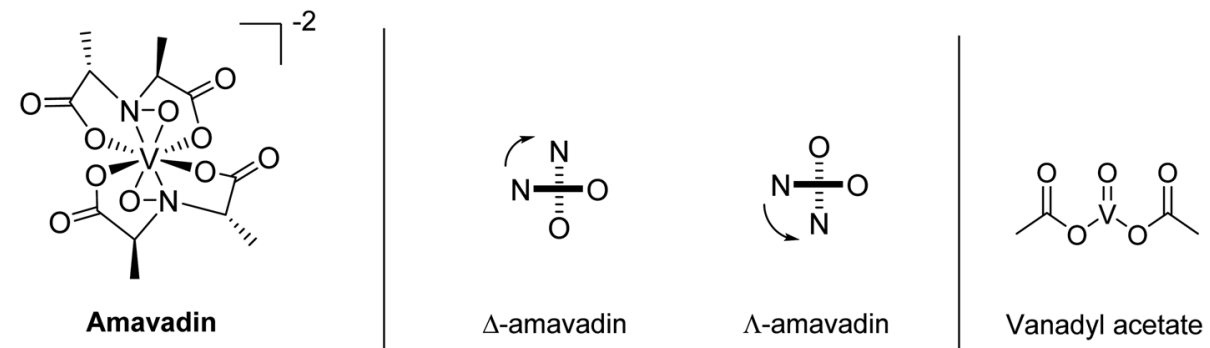

Fig. 1 Structure of amavadin, schematic representation of its $\Delta$ - and $\Lambda$-helical forms, and structure of vanadyl acetate. 
idea that amavadin is involved in the oxygen production in the fruit body. ${ }^{35}$ da Silva et al. speculated that amavadin could react with the side chains of amino acid residues of proteins, but also noted that the high coordination number of the complex makes a permanent coordination to proteins unfavorable. ${ }^{25}$ This was confirmed by a recent study, where Ugone et al. showed that only non-covalent interactions between amavadin and proteins are possible. ${ }^{36}$ Finally, the high stability of the complex over a broad $\mathrm{pH}$ range led to the suggestion that amavadin could be used as a catalyst in an acidic medium, and its chiral properties could be handy in asymmetric synthesis. ${ }^{25}$

of the many old and recent studies on amavadin and derived complexes, most explored the compounds' physicochemical properties and their catalytic behavior. However, hardly anything is published on amavadin's occurrence, biosynthesis, and distribution in A. muscaria and other macrofungi. One exception is a study by Gillard et al., where EPR data suggested that all parts of the fruit body of $A$. muscaria contained the same $\mathrm{V}$ compound. ${ }^{20}$ The only other notable exception is the work of Koch et al. from 1987, where they extracted several different mushrooms of the genus Amanita and different fruit-body parts of $A$. muscaria with water at $60{ }^{\circ} \mathrm{C}$ and then analyzed with ion-pair chromatography and UV-detection. ${ }^{17}$ They, too, found that amavadin was present in all the investigated fruit-body parts of $A$. muscaria, with concentrations between 15 and $56 \mathrm{mg} \mathrm{V} \mathrm{kg} \mathrm{g}^{-1}$ $\mathrm{dm}$. The highest concentrations were detected in the bulb samples. The concentrations accounted for only 10 to $20 \%$ of the total $\mathrm{V}$ in the samples. As possible reasons for these low percentages, the authors speculated that the extraction was maybe not quantitative, that amavadin was degraded in the extract, or that amavadin was not the only $\mathrm{V}$ species in $A$. muscaria, although they deemed the last option not very likely. ${ }^{17}$ Furthermore, Koch et al. found that amavadin is not only present in A. muscaria, but also in $A$. regalis and $A$. velatipes. ${ }^{17}$ In the case of $A$. rubescens, $A$. parcivolvata and $A$. wellsii, no clear identification of amavadin was possible, due to the low concentrations.

\subsection{Vanadium speciation analysis}

Speciation analysis of $\mathrm{V}$ is mainly focused on the determination of $\mathrm{V}(\mathrm{IV})$ and $\mathrm{V}(\mathrm{v})$ in water and soil extracts, ${ }^{37,38} \mathrm{~V}$ porphyrins in crude oil, ${ }^{39}$ and molecular size fractions in blood and organ samples, usually after the administration of different $\mathrm{V}$ compounds. ${ }^{40}$

Inductively coupled plasma mass spectrometry (ICPMS) is nowadays typically used as a sensitive, V-selective detector, but other techniques have been used in the past as well, like electrothermal atomic absorption spectroscopy, inductively coupled plasma optical emission spectroscopy or even UV. ${ }^{38}$

For blood and organ samples, size exclusion chromatography (SEC), often in combination with anion-exchange chromatography (AEC) has been used to distinguish between low-molecular mass fractions, high molecular mass fractions and transferrin-associated $\mathrm{V}^{\mathbf{4 1 , 4 2}} \mathrm{Nischwitz}$ et al. used electrospray ionization tandem mass spectrometry in addition to SEC and tentatively identified a divanadatephosphate derivate in liver cells that were exposed to an antidiabetic $\mathrm{V}$ species. ${ }^{43}$

The $\mathrm{V}$ speciation in water and soil extracts usually only consists of inorganic V(v) and V(Iv) ions. ${ }^{37}$ The speciation analysis of these samples is nevertheless challenging, because of the lability of the $\mathrm{V}$ species. If the samples are not stabilized properly, species interconversion can easily take place, especially the oxidation of $\mathrm{V}(\mathrm{IV})$ to $\mathrm{V}(\mathrm{v}) .{ }^{61}$ For this reason, most methods add a chelating agent to the samples or the mobile phase, for example ethylenediaminetetraacetate (EDTA). ${ }^{\mathbf{4 4 5}}$ The separation of the formed vanadyl and vanadate complexes is typically achieved via high performance liquid chromatography (HPLC), with ion-pair or ion-exchange chromatography. ${ }^{4-51}$ Capillary electrophoresis has been employed as well, but only in very few studies. ${ }^{52}$ Alternatively, some publications use selective extraction one of the two $\mathrm{V}$ species or solid phase extraction with selective elution, and apply the developed methods to water, soil and plant samples. ${ }^{53-55}$

There are also examples of $\mathrm{V}$ speciation analysis with X-ray absorption spectroscopy, more precisely with X-ray absorption near edge structure (XANES) spectroscopy, for example of $\mathrm{V}$ compounds in mycelium ${ }^{56}$ or ascidians. ${ }^{57}$ These studies were able to deliver information on the element's oxidation state and in some cases on its spatial distribution in the sample.

There are only a few publications that do not only distinguish between $\mathrm{V}(\mathrm{IV})$ and $\mathrm{V}(\mathrm{v})$ or between rough molecular mass fractions, or investigate other sample types than the mentioned ones. Jensen-Fontaine et al. used HPLC-ICPMS with AEC to determine $\mathrm{V}$ species in the benthic invertebrate Hyalella azteca, exposed to $\mathrm{V}^{58}$ Apart from $\mathrm{V}(\mathrm{IV})$ and $\mathrm{V}(\mathrm{v})$ ions, they also found an unknown $\mathrm{V}$ compound. They speculated that it could be $\mathrm{V}$ associated or bound to a protein or a smaller cellular molecule of $H$. azteca, but this still remains to be investigated in more detail. Kütter et al. used SEC and AEC-UV-ICPMS as well as matrix-assisted laser desorption/ionization (MALDI) time of flight mass spectrometry for $\mathrm{V}$ speciation analysis in plankton. ${ }^{59}$ They found a V-containing compound with a mass of 8-16 kDa, but concluded that it was not possible to further identify this compound. Finally, in 1987, Koch et al. used ion-pair chromatography with UV detection to determine amavadin in different parts of Amanita muscaria, as already described earlier. ${ }^{17}$ This is the only described chromatographic method for the investigation of amavadin until now, but it is neither sensitive nor selective, nor was it validated. The authors themselves write that the unambiguous identification of amavadin is not possible in samples with low $\mathrm{V}$ concentrations, due to a high background and "not very characteristic UV spectra". ${ }^{17}$ While this work was useful for a rough estimate of the amavadin concentration in the samples of Amanita muscaria back in 1987, it does not meet the criteria for a modern, state-of-the-art analytical method in 2021.

Thus, we developed a sensitive method for the detection of amavadin and related V species with HPLC-ICPMS. The method was validated and applied to three fruit-body samples of $A$. muscaria, divided into their different parts. 


\section{Experimental}

\subsection{Chemicals and instruments}

Ultrapure water $(18.2 \mathrm{M} \Omega \mathrm{cm})$ was used throughout the study. All chemicals were purchased from common chemical suppliers and used as received without further purification, if not described otherwise. A detailed description of all chemicals, including the purity and supplier, can be found in the ESI (Section 1 "Chemicals and instruments" $\dagger$ ). The employed instruments are also listed in more detail in the ESI (Section $1 \dagger$ ) and are only described in an abbreviated version here.

Air and moisture sensitive reactions were carried out following the standard Schlenk technique with $\mathrm{Ar}$ as an inert atmosphere. NMR spectra were recorded on a Bruker Advance III $300 \mathrm{MHz}$ NMR spectrometer in deuterated solvents. IR spectra were recorded on a Bruker Alpha FTIR spectrometer.

Electrospray mass spectrometry (ESMS) was performed with a 6120 Quadrupole LC/MS (Agilent Technologies). A 1260 Infinity HPLC (Agilent Technologies) and a Nucleodur C18 Pyramid column (Macherey-Nagel) were used to separate the compounds for further analysis with ESMS. Total V concentrations were determined with a 7700x ICPMS (Agilent Technologies).

For speciation analysis, a 1260 Infinity HPLC (Agilent Technologies) was coupled to a 7700x ICPMS or a tandem ICPMS (ICPMS/MS, 8900, Agilent Technologies). A silica-based strong anion-exchange column (Zorbax SAX, $4.6 \times 150 \mathrm{~mm}, 5 \mu \mathrm{m}$, Agilent Technologies) was used for the separation of the $\mathrm{V}$ species.

The water content of the mushroom samples was determined with a SMART Trac II Moisture \& Fat Analyzer (CEM). An Ultraclave IV (MLS GmbH) was used for microwave assisted digestions. Extracts were centrifuged on a Rotina $420 \mathrm{R}$ (Hettich Lab Technology). Nylon syringe filters $(0.22 \mu \mathrm{m}$, Simplepure) were used for filtering the extracts prior to analysis.

\subsection{Synthesis}

2.2.1 Dimethyl 2,2'-(hydroxyazanediyl) $\left(2 R, 2^{\prime} R\right)$-dipropionate (1). In a flame dried, Ar flushed Schlenk flask, methyl-Llactate $(1.40 \mathrm{~g}, 13.4 \mathrm{mmol})$ was dissolved in dry methylene chloride $(40 \mathrm{~mL})$, and the solution was cooled to $-60{ }^{\circ} \mathrm{C} . \mathrm{Tf}_{2} \mathrm{O}$ ( $1 \mathrm{M}$ in dry methylene chloride, $14.7 \mathrm{~mL}$ ) was added, followed by lutidine $(3.16 \mathrm{~g}, 29.5 \mathrm{mmol})$ after 10 minutes which caused the solution to turn pale red immediately. After another 10 minutes, hydroxylamine solution ( $1 \mathrm{M}$ in $\mathrm{MeOH}, 5.36 \mathrm{~mL}$ ) was added, and the cooling bath was removed. The reaction mixture was slightly opaque, but after warming up to room temperature, all solids were dissolved. After stirring for $16 \mathrm{~h}$, the mixture was quenched by the addition of water $(20 \mathrm{~mL})$, the phases were separated, and the aqueous phase was extracted with ethyl acetate $(2 \times 20 \mathrm{~mL})$. The combined organic phases were dried $\left(\mathrm{MgSO}_{4}\right)$ and the solvent was removed on a rotary evaporator. Purification by $\mathrm{SiO}_{2}$ flash chromatography gave $664 \mathrm{mg}(48 \%)$ of 1 as a pale-yellow resin. NMR spectra can be found in the ESI (Fig. S1 and S2†).
${ }^{1} \mathrm{H}$ NMR $\left(300 \mathrm{MHz}, \mathrm{CDCl}_{3}\right) \delta=5.79(\mathrm{~s}, 1 \mathrm{H}), 5.29(\mathrm{~s}, 2 \mathrm{H}), 3.71$ $(\mathrm{q}, J=6.9,2 \mathrm{H}), 3.70(\mathrm{~s}, 6 \mathrm{H}), 1.33(\mathrm{~d}, J=6.9,6 \mathrm{H}) .{ }^{13} \mathrm{C}$ NMR $(75$ $\left.\mathrm{MHz}, \mathrm{CDCl}_{3}\right) \delta=173.2,60.9,53.4,52.2,12.6$.

2.2.2 (2R, $\left.2^{\prime} R\right)-2,2^{\prime}-($ Hydroxyazanediyl)dipropionic acid (2). In a round bottom flask, $\mathrm{KOH}(85 \%$ by weight, $310 \mathrm{mg}, 6.5$ $\mathrm{mmol})$ was dissolved in water $(20 \mathrm{~mL}) .1(532 \mathrm{mg}, 2.59 \mathrm{mmol})$ was added, and the mixture was stirred at room temperature for 1 hour. The product suspension was acidified to a $\mathrm{pH}$ of approx. 5 by the addition of $2 \mathrm{M} \mathrm{HCl}$. Upon addition of $\mathrm{Zn}(\mathrm{OAc})_{2}(1 \mathrm{M}$ in $\mathrm{H}_{2} \mathrm{O}, 3 \mathrm{~mL}$ ), a colorless precipitate was formed. The suspension was transferred into test tubes, centrifuged for ten minutes, and the liquid was disposed of. The solid was washed twice with water and centrifuged again. The isolated colorless solid was dissolved in $5 \mathrm{M} \mathrm{HCl}$ (approx. $4 \mathrm{~mL}$ ) and applied onto a column packed with Dowex ${ }^{\circledR} 50 \mathrm{WX} 2$ hydrogen form ion-exchange resin that was thoroughly rinsed with water prior to use, until the eluent had a steady $\mathrm{pH}$ of $\sim 4$. Fractions were collected and checked for product by spotting on a thin layer chromatographic plate, thorough drying and derivatization with $\mathrm{KMnO}_{4}$ staining solution. The removal of water on a rotary evaporator gave $359 \mathrm{mg}$ ( $86 \%)$ of 2 as a colorless solid. See ESI, Fig. S3 and $\mathrm{S} 4 \uparrow$ for NMR spectra and Fig. $\mathrm{S} 5 \dagger$ for the IR spectrum.

${ }^{1} \mathrm{H}$ NMR $\left(300 \mathrm{MHz}, \mathrm{D}_{2} \mathrm{O}\right) \delta=4.02(\mathrm{q}, J=7.0,2 \mathrm{H}), 1.41(\mathrm{~d}, J=$ 7.0, 6H). ${ }^{13} \mathrm{C} \mathrm{NMR}\left(75 \mathrm{MHz}, \mathrm{D}_{2} \mathrm{O}\right) \delta=174.5,62.7,11.6$. ESMS: $m /$ $z$ calc for $[\mathrm{M}+1]^{+}: 178$, found: 178. IR: $1747\left(\nu_{\mathrm{CO}}\right) \mathrm{cm}^{-1}$.

2.2.3 Vanadyl acetate, $\operatorname{VO}(\mathrm{OAc})_{2}$. A suspension of $\mathrm{V}_{2} \mathrm{O}_{5}$ $(1.00 \mathrm{~g}, 5.49 \mathrm{mmol})$ in acetic anhydride $(50 \mathrm{~mL})$ was brought to a reflux for $3 \mathrm{~h}$, during which the suspension turned from orange to pale green. The hot product suspension was filtered, and the residue was washed with chloroform $(3 \times 5 \mathrm{~mL})$ and dried in vacuo to give $1.87 \mathrm{~g}$ (92\%) of vanadyl acetate (Fig. 1) as a pale green solid. The IR spectrum is shown in ESI, Fig. S6. $\dagger$

ESMS: $\mathrm{m} / \mathrm{z}$ calculated for $[\mathrm{M}+1]^{+}: 186 ; \mathrm{m} / \mathrm{z}$ found: 158 , corresponding to $\left[\mathrm{VO}(\mathrm{OOCH})_{2}+\mathrm{H}\right]^{+}-$owing to the formic acid in the mobile phase. IR: $1508\left(\nu_{\mathrm{CO}}\right), 894\left(\nu_{\mathrm{vO}}\right) \mathrm{cm}^{-1}$.

2.2.4 Amavadin. A solution of $2(219 \mathrm{mg}, 1.24 \mathrm{mg})$ in water $(5 \mathrm{~mL})$ was added to a suspension of vanadyl acetate $(114 \mathrm{mg}$, $0.62 \mathrm{mmol})$ in water $(3 \mathrm{~mL})$. The mixture was stirred for 1 hour and the formed blue solution was filtered through a cotton plug, and the solvent was removed on a rotary evaporator. The crude product was dried in vacuo to give a $243 \mathrm{mg}$ bright blue solid. It was a mixture of amavadin $(74 \% \mathrm{w} / \mathrm{w}, 0.45 \mathrm{mmol}, 73 \%$ yield $)$ and vanadyl acetate. Because of the paramagnetic character of $\mathrm{V}(\mathrm{Iv})$, no NMR of the product could be obtained. The IR spectrum is shown in ESI, Fig. S7. $\dagger$

ESMS: $m / z$ calc for $[\mathrm{M}+3 \mathrm{H}]^{+}: 402$, found: 402 . IR: 1561 $\left(\nu_{\mathrm{CO}}\right) \mathrm{cm}^{-1}$.

\subsection{Confirmation of the structure and concentration}

2.3.1 Structural confirmation by ESMS. For HPLC-ESMS measurements, a reversed-phase Nucleodur C18 Pyramid column was used as the stationary phase. The mobile phase consisted of $0.1 \%$ formic acid in water (A) and methanol (B), with $70 \% \mathrm{~A}$ and $30 \% \mathrm{~B}$. The ESMS was operated in positive ion mode. In scan mode, the $\mathrm{m} / \mathrm{z}$ range $120-600$ was scanned, and in SIM mode, $\mathrm{m} / \mathrm{z} 158,186$ and 402 were monitored. More 
details on the settings of the HPLC-ESMS measurements can be found in the ESI. Amavadin and vanadyl acetate were dissolved in ultrapure water (although the latter one was only poorly soluble $^{60}$ ) for the ESMS analyses.

2.3.2 Determination of the standard's concentration via ICPMS. Amavadin was dissolved in ultrapure water and then further diluted with $10 \%$ nitric acid. Vanadyl acetate was dissolved in $10 \%$ nitric acid and further diluted as well. The $\mathrm{V}$ concentration of both standards was determined with ICPMS in He collision gas mode. Details on the measurements are given in Table 1. An external calibration was used for quantification, with a V standard in $10 \%$ nitric acid, at concentrations from 0.1 to $10 \mu \mathrm{g} \mathrm{L}^{-1}$. The Standard Reference Material (SRM) 1640a (trace elements in natural water, $n=1$ ) was used to evaluate the measurement's accuracy (trueness: 93\%).

Ge $\left(m / z 74,200 \mu \mathrm{g} \mathrm{L}^{-1}\right.$ in $10 \%$ nitric acid) was used as the internal standard. It was added online via a T-piece in front of the nebulizer to the calibration standards and the sample. Its tubing's diameter was $1 / 4$ of the sample tubing.

\subsection{HPLC-ICPMS method development}

Because amavadin carries two negative charges, an anionexchange column (Zorbax SAX) and an aqueous mobile phase with ammonium citrate (citric acid, $\mathrm{pH}$ adjustment with concentrated aqueous ammonia) were employed. $\mathrm{Na}_{2}$ EDTA (10

Table 1 Details on the ICPMS settings, the optimized HPLC-ICPMS method and the parameters during method optimization

\begin{tabular}{|c|c|}
\hline \multicolumn{2}{|l|}{ ICPMS measurements } \\
\hline Instrument & Agilent 7700x \\
\hline Collision gas mode & $\mathrm{He}\left(5 \mathrm{~mL} \min ^{-1}\right)$ \\
\hline Monitored $\mathrm{m} / \mathrm{z}$ & $51(\mathrm{~V}), 74(\mathrm{Ge}$, internal standard $)$ \\
\hline Integration time & $0.1 \mathrm{~s}$ per $\mathrm{m} / \mathrm{z}$ \\
\hline Intensity of $1 \mu \mathrm{g} \mathrm{V} \mathrm{L}{ }^{-1}$ & $40 \mathrm{kcps}$ \\
\hline $\begin{array}{l}\text { Oxide ratio }(\mathrm{m} / \mathrm{z} 156 / 140 \\
\left.{ }^{140} \mathrm{Ce}^{16} \mathrm{O}^{+} /{ }^{140} \mathrm{Ce}^{+}\right)\end{array}$ & $0.5 \%$ \\
\hline $\begin{array}{l}\text { Doubly charged ratio }(\mathrm{m} / z \mathrm{z} \text { / } \\
\left.140 ;{ }^{140} \mathrm{Ce}^{2+} /{ }^{140} \mathrm{Ce}^{+}\right)\end{array}$ & $1.3 \%$ \\
\hline Signal stability (RSD) & $2-3 \%$ \\
\hline
\end{tabular}

Optimized HPLC-ICPMS method

Instruments

Collision gas mode

Monitored $\mathrm{m} / \mathrm{z}$

Integration time

Column

Mobile phase

Flow rate

Column temperature

Injection volume

Injection speed

Evaluated parameters during HPLC-ICPMS method optimization (starting values in bold)

Concentrations

$\mathrm{pH}$ values

Temperatures
$\mathrm{mM}$ ) was added to the mobile phase for complexing all present smaller $\mathrm{V}$ species and thus prohibiting unwanted precipitation or interconversion. Different column temperatures $\left(5-45{ }^{\circ} \mathrm{C}\right)$, concentrations of citric acid (2-50 mM) and $\mathrm{pH}$ values $(4.0-7.5)$ were tested to optimize the separation method. The evaluated parameters and also the final method are summarized in Table 1. A standard containing $10 \mu \mathrm{g} \mathrm{V} \mathrm{L}{ }^{-1}$ of amavadin and vanadyl acetate was used for the experiments, dissolved and diluted in the initial mobile phase (Table 1, "starting values").

The peaks were integrated at the baseline, with a vertical division at the valley between the two amavadin isomers.

The resolution $R$ of the amavadin's two isomers was calculated according to the following formula, where $t_{\mathrm{R} 1}$ and $t_{\mathrm{R} 2}$ are the retention times at the peak maxima, and $w_{0.5 \mathrm{~h} 1}$ and $w_{0.5 \mathrm{~h} 2}$ are the peak widths at $50 \%$ peak height.

$$
R=1.18 \times \frac{\left(t_{\mathrm{R} 2}-t_{\mathrm{R} 1}\right)}{\left(w_{0.5 \mathrm{~h} 1}+w_{0.5 \mathrm{~h} 2}\right)}
$$

The optimized method was validated by performing a calibration from 0.1 to $100 \mu \mathrm{g} \mathrm{V} \mathrm{L}^{-1}$ (calibration points: $0,0.1,0.5$, $1,5,10,50$, and $100 \mu \mathrm{g} \mathrm{V} \mathrm{L}{ }^{-1}$ ) of amavadin (sum of both isomers) and vanadyl acetate. The two standards were mixed together and diluted with the mobile phase (Table 1). The lowest standard was injected 5 times to determine the limit of detection (LOD) and limit of quantification (LOQ). The LOD was calculated as three times the standard deviation, and the LOQ ten times the standard deviation of the lowest standard. A

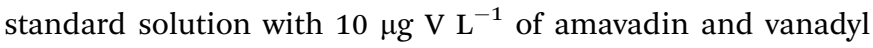
acetate was injected six times over the course of a 24 hour long measurement to evaluate the method's stability. The SRM 1640a ( $n=1$ ) was diluted $1+1$ with the mobile phase and analyzed with the developed method to determine the method's accuracy.

\subsection{Mushroom samples}

2.5.1 Collection and cleaning. Three fruit bodies of Amanita muscaria (named A, B and C) were collected in Lachtal, Austria, in August 2020. The samples were kept at $4{ }^{\circ} \mathrm{C}$ overnight, and then brought to the lab and thoroughly cleaned with a small brush and moist paper towels. They were separated into their different parts, as shown in Fig. 2, namely the cap, stipe, gills, cap skin (hereafter referred to as "skin", removed from the cap with a scalpel) and the outer part of the bulb (the lower part of the stipe), which was a mixture of bulb, mycelium and residual soil (hereafter referred to as "bulb"). In order to keep as much mycelium as possible, we refrained from removing the soil too thoroughly from the bulb samples. Each sample was homogenized with a small blender (M 20 Universal mill, IKA, Staufen, Germany). The homogenates were then stored at $4{ }^{\circ} \mathrm{C}$ and prepared for total element determination and speciation analysis within 24 hours of cleaning. The water content of the homogenized samples was determined with a SMART Trac II Moisture \& Fat Analyzer.

2.5.2 Sample preparation. For the determination of the total $\mathrm{V}$ concentrations, around $2 \mathrm{~g}$ of cap, stipe and gills, and 


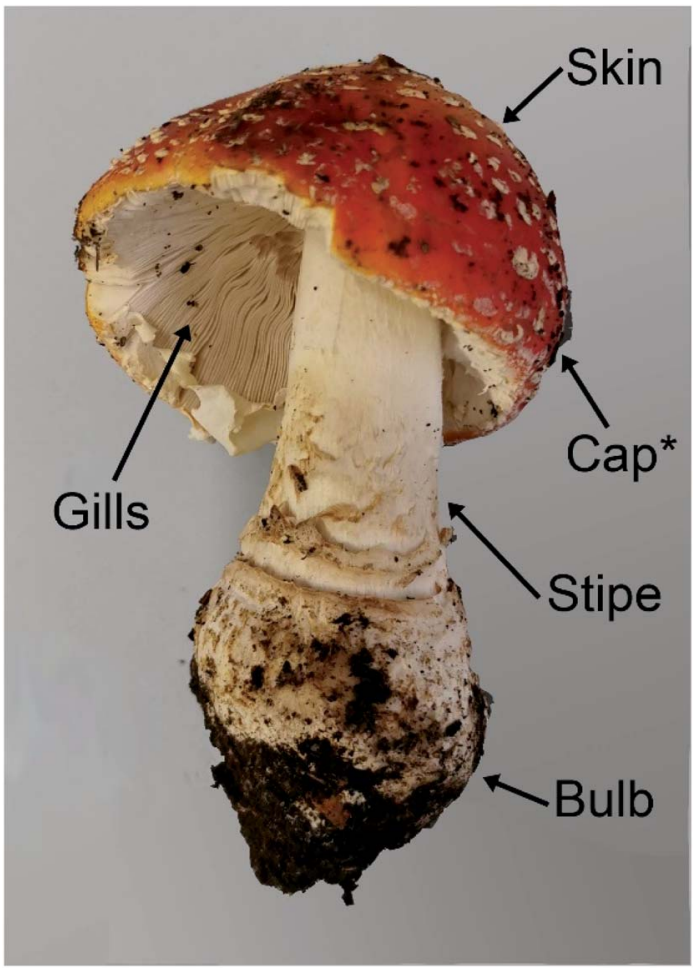

Fig. 2 Different parts of the fruit body of Amanita muscaria. *The cap flesh is beneath the skin and not visible.

0.3-1 g of skin or bulb (less biomass was available) were weighed into quartz vessels, each sample in triplicates. $5 \mathrm{~mL}$ of nitric acid were added ( $2 \mathrm{~mL}$ in the case of skin samples), and the samples were digested in a microwave assisted autoclave, with a loading pressure of $40 \mathrm{bar} \mathrm{Ar}$ and a maximum temperature of $250^{\circ} \mathrm{C}$. The digests were diluted with ultrapure water to a final acidity of $10 \%(\mathrm{v} / \mathrm{v})$ nitric acid. For quality control, the SRM 1573a (tomato leaves, $n=4)$ and blanks $(n=6)$ were digested as well.

For V speciation analysis, around $2 \mathrm{~g}$ of cap, stipe and gills and $1 \mathrm{~g}$ of bulb and skin were extracted with $20 \mathrm{~mL}(10 \mathrm{~mL}$ in the case of the bulb and skin) of mobile phase (Table 1). The parts of sample A were extracted in triplicates, the parts of samples B and $\mathrm{C}$ only one time each, and three blank samples were prepared. After the addition of the mobile phase, the samples were thoroughly mixed, put in an ultrasonic bath for 20 minutes, centrifuged for 10 minutes, and then filtered through $0.22 \mu \mathrm{m}$ Nylon filters. The extracts were subjected to HPLCICPMS analysis without further dilution. For the determination of the extraction efficiency, the extracts were diluted $1+99$ with $10 \%(\mathrm{v} / \mathrm{v})$ nitric acid.

\subsubsection{Determination of total $\mathrm{V}$}

The total $\mathrm{V}$ concentrations in the digests and in the diluted extracts were measured with ICPMS, as already described earlier for the amavadin standard (Section 2.3.2). In addition to the digested SRM 1573a, the SRM 1640a $(n=1)$ was diluted $1+9$ $(10 \%(\mathrm{v} / \mathrm{v})$ nitric acid) and analyzed as well.
2.5.4 V speciation analysis. The pure extracts were transferred to polypropylene HPLC vials with polyethylene caps and a natural rubber septum, and investigated with the newly developed V speciation analysis method. One replicate of each A sample was monitored for 60 minutes to look for strongly retained compounds. An external calibration was prepared, including amavadin and vanadyl acetate at concentrations between 0.1 and $100 \mu \mathrm{g} \mathrm{V} \mathrm{L}^{-1}$ (plus a blank). In the case of amavadin, the calibration line was calculated for the sum of its two isomers. Since the response of ICPMS is compoundindependent, this calibration was used for the quantification of the two individual isomers and also for unknown $\mathrm{V}$ species.

The identity and accuracy of amavadin and vanadyl acetate in the mushroom extracts were confirmed by spiking one sample (gills A) online via a HPLC autosampler with standard solutions. For the confirmation of amavadin, $2 \mu \mathrm{L}$ of extract were spiked with $20 \mu \mathrm{L}$ of $100 \mu \mathrm{g} \mathrm{V} \mathrm{L}{ }^{-1}$ of amavadin (see ESI, Fig. S11 $\dagger$ ). In the case of vanadyl acetate, $20 \mu \mathrm{L}$ of extract were spiked with $1 \mu \mathrm{L}$ of a $5 \mu \mathrm{g} \mathrm{V} \mathrm{L}{ }^{-1}$ solution of vanadyl acetate. The ratios were selected to achieve a doubling of the peaks in question.

\section{Results and discussion}

\subsection{Synthesis}

Amavadin was synthesized employing a slightly modified version of the procedure reported by Hubregtse et al. ${ }^{32}$ The ligand was prepared from lactic acid methyl ester, starting with the conversion of the hydroxyl moiety into the corresponding triflate with triflic anhydride in the presence of lutidine, and subsequent nucleophilic substitution with hydroxylamine to give 1 (see Scheme 1). The hydrolysis of the methyl esters in aqueous $\mathrm{KOH}$ and precipitation with zinc acetate gave the desired ligand as the corresponding zinc salt. Ion exchange chromatography yielded a free ligand (2), that reacted with vanadyl acetate to form amavadin. A sample of $243 \mathrm{mg}$ of dark blue crystals was obtained this way. Later analyses with ICPMS, HPLC-ICPMS and co-chromatography with vanadyl acetate revealed that $26 \%(\mathrm{w} / \mathrm{w})$ of the obtained solid still was vanadyl acetate, and $74 \%(\mathrm{w} / \mathrm{w})$ was amavadin (see also Section 3.2). This means that amavadin was synthesized with a yield of $180 \mathrm{mg}$, or $73 \%$.

Due to the $\mathrm{d}^{1}$ electron configuration of the $\mathrm{V}(\mathrm{IV})$ center, amavadin and vanadyl acetate both are paramagnetic, and thus NMR could not be performed on the product. The oxidation of $\mathrm{V}(\mathrm{Iv})$ to $\mathrm{V}(\mathrm{v})$ in DMSO was attempted, as reported in the literature. ${ }^{31} \mathrm{~A}$ sample of amavadin in DMSO- $d_{6}$ was exposed to the atmosphere for several weeks, which caused the solution to turn from blue to red; however still no NMR spectrum was obtained. It is unclear whether amavadin could not be oxidized completely or the presence of paramagnetic vanadyl acetate made the sample immeasurable by standard NMR techniques.

The successful synthesis of amavadin was proven by ESMS and IR-spectroscopy. The IR spectrum (ESI, Fig. S7 $\dagger$ ) shows distinct peaks at wavenumbers reported in the literature. ${ }^{32}$ The mass spectrum of amavadin is shown in ESI, Fig. S8 and S9. $\dagger$ 

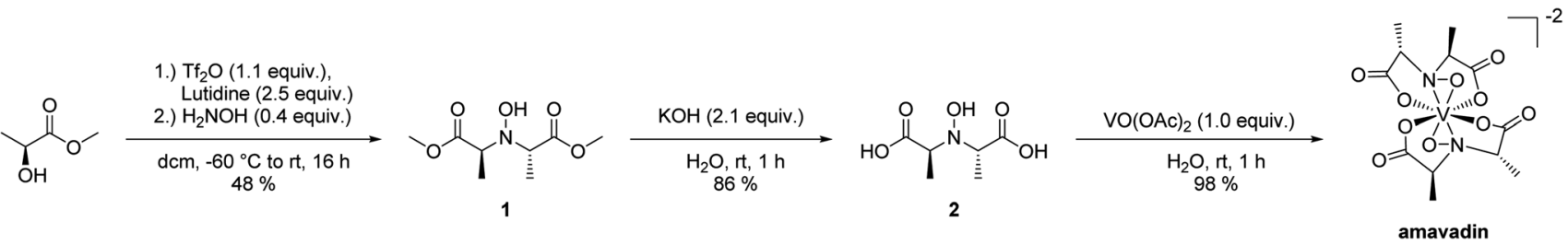

Scheme 1 Synthesis of amavadin starting from (L)-lactic acid methyl ester.

The molecule peak for $[\mathrm{M}+3 \mathrm{H}]^{+}$can be seen at $m / z 402$, besides lower peaks at $m / z 401$ and 403, and also sodium adducts at $m / z$ 423, 424 and 425 are visible.

\subsection{Method development}

Because of the negative charges of amavadin, even at very low $\mathrm{pH}$ values, ${ }^{22}$ anion-exchange chromatography was selected as the best option for its chromatographic separation. Citric acid at $\mathrm{pH} 5.3$ (adjusted with ammonia) in ultrapure water was selected as the starting point for the mobile phase. At this $\mathrm{pH}$, citric acid has a dianionic character ( $\mathrm{p} K_{\mathrm{a}}$ values: $3.13,4.76$ and $6.40^{61}$ ), like amavadin, which should increase the elution strength of the buffer.

Amavadin was at first dissolved in ultrapure water. During method development, it was found that there was another Vcontaining compound in the amavadin standard. The first logical candidate was vanadyl acetate, the precursor that was used in the synthesis of amavadin. Thus, vanadyl acetate was dissolved in the initial mobile phase (Table 1, "starting values") and analyzed along with amavadin. The first results from ESMS and HPLC-ICPMS showed that the impurity was indeed vanadyl acetate, which was subsequently included in the calibration standards. Quantification via ICPMS and HPLC-ICPMS (in the latter case with vanadyl acetate as the quantification standard and SRM 1640a as the reference material) showed that $43 \%$ of the total V of the "amavadin standard" was present in the form of vanadyl acetate (meaning that $26 \%$ of the solid material is vanadyl acetate).

Due to the poor solubility of vanadyl acetate in pure water, the amavadin standard was henceforth also dissolved in the mobile phase, to ensure that the vanadyl acetate moiety in the amavadin standard was quantitatively dissolved. In order to have similar concentrations of the two $\mathrm{V}$ species, additional vanadyl acetate was added to the amavadin standard. Over the course of method development, the relative peak areas of both species remained constant, which indicates that no interconversion of the two species was taking place.

$\mathrm{Na}_{2}$ EDTA was included in the mobile phase to ensure a quantitative elution of vanadyl acetate. This can also be beneficial for other small V species, which were not a target of the developed method, but can nevertheless occur in environmental samples. Vanadyl acetate (that is to say, very likely vanadyl complexed by EDTA) was eluting significantly earlier than amavadin as a clean, symmetric peak at all settings of the method development and will not be further discussed in this context.
Finally, $20 \mathrm{mM}$ citric acid at pH 5.3 (adjusted with ammonia) with $10 \mathrm{mM} \mathrm{Na}{ }_{2}$ EDTA was selected as the starting point (see also Table 1). The column oven was set at $25^{\circ} \mathrm{C}$, and the flow rate was $1 \mathrm{~mL} \mathrm{~min}^{-1}$. With these first settings, a double peak appeared in the chromatogram at 7.1 and 7.5 minutes, corresponding to the two isomers of amavadin. To achieve a good resolution of these two peaks, the buffer concentration and $\mathrm{pH}$ value, as well as the column temperature, were optimized. The evaluated conditions are summarized in Table 1, and the resulting chromatograms are shown in Fig. 3.

The concentration of citric acid was varied between 2 and $50 \mathrm{mM}$. As can be seen from the resolution values depicted in Fig. $4 \mathrm{~A}$ and the chromatograms in Fig. 3A, lowering the concentration of the buffer improved the separation of the two isomers. However, this also increased the retention time significantly, up to 20 and 21 minutes at $2 \mathrm{mM}$ citric acid. Based on these findings, we found that a concentration of $10 \mathrm{mM}$ provides a good balance between the retention time (second isomer: $8.9 \mathrm{~min}$ at the peak maximum, resulting in a total chromatogram time of $10 \mathrm{~min})$ and resolution $(R=0.56)$ of the amavadin peaks.

As the next step, the column temperature was varied between 5 and $45{ }^{\circ} \mathrm{C}$. With colder settings, the two peaks were better separated (Fig. 3 and 4B) but also slightly broadened. There was not much difference between 5 and $10{ }^{\circ} \mathrm{C}$, and so $10{ }^{\circ} \mathrm{C}$ was selected as the best option $(R=0.80)$. However, it was later observed that under the given laboratory conditions longer experiments at $10{ }^{\circ} \mathrm{C}$ led to condensation in the column oven, which eventually resulted in a leak error in the HPLC. To overcome this problem, the temperature was slightly increased to $13{ }^{\circ} \mathrm{C}$. This enabled a stable measurement for more than 24 hours, with still good resolution.

Finally, the influence of the $\mathrm{pH}$ value on the separation was evaluated. As can be seen in Fig. 3C and 4C, the two isomers were not separated any more at $\mathrm{pH}$ values above 6.5. Lower $\mathrm{pH}$ values led to a higher resolution, but while the retention times were 13.4 and 14.4 minutes at pH $5.0(R=0.90)$, they increased dramatically to over 26 minutes at $\mathrm{pH} 4.5$ and more than 60 minutes at $\mathrm{pH}$ 4.0. This is not surprising, because citric acid will only have one negative charge at those $\mathrm{pH}$ values, while amavadin will still have a charge of -2 .

In summary, as can also be seen in Table 1, the final method included a Zorbax SAX $(4.6 \times 150 \mathrm{~mm} 5 \mu \mathrm{m})$ silica-based anionexchange column and a mobile phase of $10 \mathrm{mM}$ citric acid, $\mathrm{pH}$ 5.0 , and $10 \mathrm{mM} \mathrm{Na}_{2}$ EDTA. The $\mathrm{pH}$ was adjusted with ammonia. The flow rate was $1.0 \mathrm{~mL} \mathrm{~min}^{-1}$ and the column temperature 


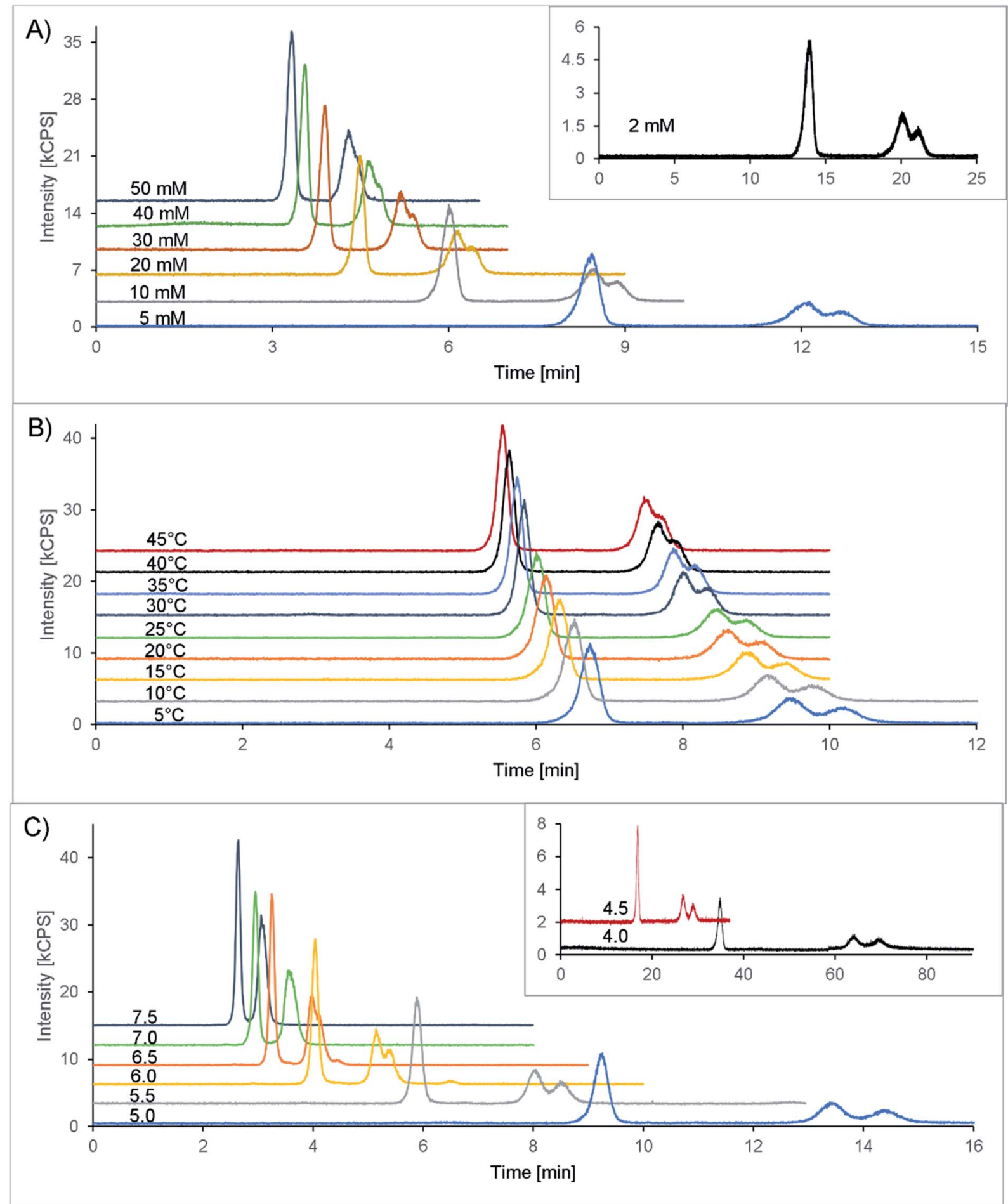

Fig. 3 HPLC-ICPMS chromatograms ( $\mathrm{V}$ at $\mathrm{m} / \mathrm{z}$ 51) of amavadin $(5 \mu \mathrm{g} \mathrm{V} \mathrm{L}-1$, later-eluting double peak, corresponding to the two isomers) and vanadyl acetate $\left(5 \mu \mathrm{g} \mathrm{V} \mathrm{L}{ }^{-1}\right.$, first peak) during method optimization. (A) Varying concentration of citric acid, at $25^{\circ} \mathrm{C}$ and $\mathrm{pH} 5.3$. The lowest concentration, $2 \mathrm{mM}$, is shown in the inset due to the much longer retention times. (B) Varying temperature, at $10 \mathrm{mM}$ citric acid and pH 5.3. (C) Varying $\mathrm{pH}$, at $10 \mathrm{mM}$ citric acid and $10^{\circ} \mathrm{C}$. The chromatograms at $\mathrm{pH} 4.0$ and 4.5 are shown in the inset due to the much longer retention times. Offsets of the $y$-axis in $\mathrm{A}, \mathrm{B}$ and $\mathrm{C}:+3 \mathrm{kcps}$ from the previous line. Exception: $+1.5 \mathrm{kcps}$ for $\mathrm{pH} 4.5$ in the inset of $\mathrm{C}$.

$13{ }^{\circ} \mathrm{C}$. The injection volume was set to $25 \mu \mathrm{L}$, and the injection speed to $100 \mu \mathrm{L} \min ^{-1}$.

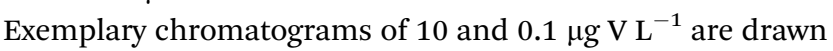
in Fig. 5. Note that the retention times are a bit longer than in the chromatograms obtained during method development (Fig. 3). An already used column was employed during method development. To make sure that no previous use had led to a modification of the stationary phase and therefore influence 

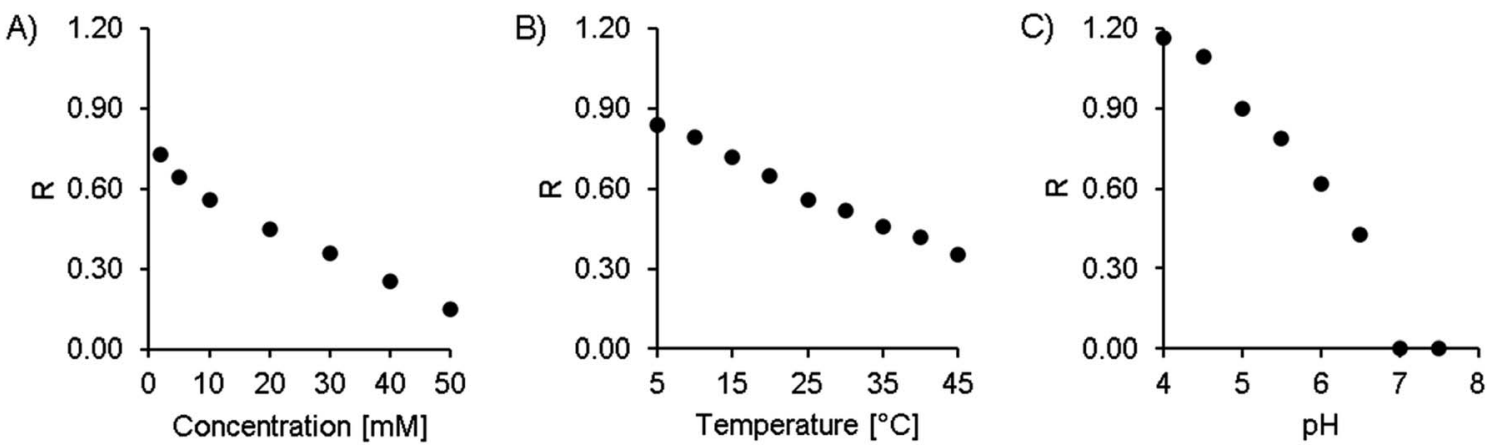

Fig. 4 Resolution of the two amavadin isomers at different chromatographic settings. (A) Varying concentration of citric acid, at $25^{\circ} \mathrm{C}$ and $\mathrm{pH}$ 5.3. (B) Varying temperature, at $10 \mathrm{mM}$ citric acid and $\mathrm{pH}$ 5.3. (C) Varying $\mathrm{pH}$, at $10 \mathrm{mM}$ citric acid and $10{ }^{\circ} \mathrm{C}$.

the separation of amavadin, a virgin column was used for method validation and application to mushroom samples. As mentioned, this led to an increase in the retention times, but the resolution of the two isomers was not affected.

\subsection{Method validation}

Although the two isomers of amavadin were almost baselineseparated, they were considered as one compound for method validation and calibration. The values obtained for the individual isomers were used to calculate the ratio of the two isomers.

The method's figures of merit are listed in Table 2. They include the LOD, LOQ, correlation coefficient $R$, stability of a 10 $\mu \mathrm{g} \mathrm{V} \mathrm{L}^{-1}$ standard during a 24 hour measurement and the average repeatability of three replicates of the five mushroom parts of sample A. The low LODs of 0.04 and $0.05 \mu \mathrm{g} \mathrm{V} \mathrm{L}{ }^{-1}$ for vanadyl acetate and amavadin, respectively, allow the detection of traces of amavadin or similar species. With a dilution factor of 10 (due to the extraction process), the LODs for mushroom samples are still below $1 \mu \mathrm{g} \mathrm{V} \mathrm{kg}{ }^{-1}$ (namely 0.4 and $0.5 \mu \mathrm{g} \mathrm{V}$ $\left.\mathrm{kg}^{-1}\right)$.

The method is very stable; the detected amavadin concentrations only vary by around $2.6 \%$ (2.8\% for vanadyl acetate) in the re-measured standard. Also, for the mushroom samples, the repeatability is lower than $5 \%$. The amavadin concentrations in the three replicates of sample A varied between 1.7 and $5.6 \%$ for the five different fruit-body parts, while the variations of the vanadyl acetate concentrations were $4.6 \pm 2.1 \%$. The highest relative standard deviations (RSDs) were found in the skin sample $(5.6 \%$ and $7.8 \%$ for amavadin and vanadyl acetate, respectively), which can be explained by the difficult homogenization of this part of the mushroom. The accuracy of the measured SRM, NIST 1640a, was excellent, namely $98.4 \%$ of the total V. The V speciation in this SRM is not defined, but V had the same retention time as vanadyl acetate (probably eluted as vanadyl EDTA). The method's accuracy was further confirmed by the recoveries after online spiking of an extract (gills A) with amavadin and vanadyl acetate, which were 90 and 105\%, respectively. Another indirect proof of the method's accuracy is
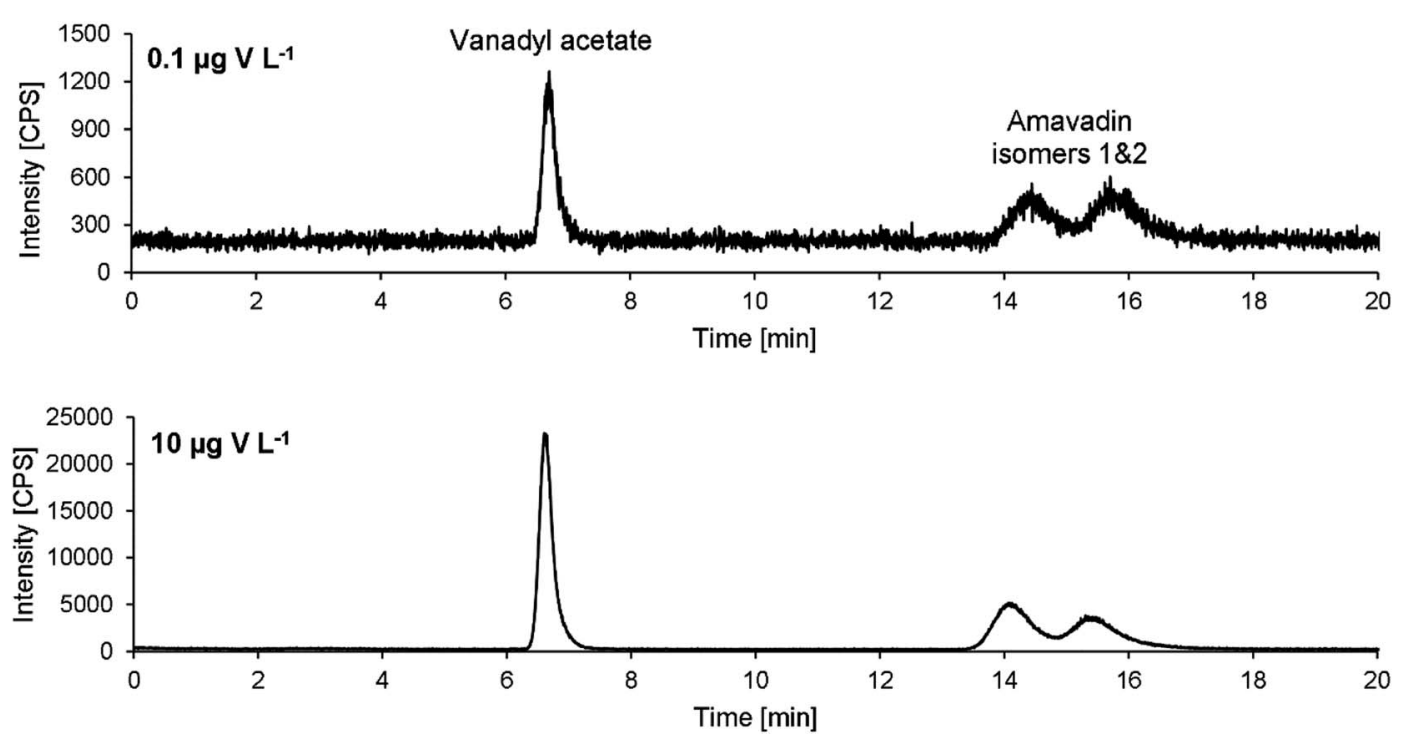

Fig. 5 HPLC-ICPMS chromatograms of $V(m / z 51)$ of the lowest $\left(0.1 \mu \mathrm{g} \mathrm{L} \mathrm{L}^{-1}\right)$ and a medium concentrated $\left(10 \mu \mathrm{g} \mathrm{L}^{-1}\right)$ standard of amavadin and vanadyl acetate, obtained with the optimized method parameters. 
Table 2 Method figures of merit; calibration range: $0.1-100 \mu \mathrm{g} \mathrm{V} \mathrm{L}{ }^{-1}$; stability $=\mathrm{RSD}$ of six times re-measured $10 \mu \mathrm{g} \mathrm{V}{ }^{-1}$ standard; repeatability $=$ mean \pm standard deviation of the RSD of the three replicates of each mushroom part of sample A. Recovery $=$ results from online spiking an extract (gills A) with the standards

\begin{tabular}{llllll}
\hline & $\begin{array}{l}\text { LOD }[\mu \mathrm{g} \mathrm{V} \\
\left.\mathrm{L}^{-1}\right]\end{array}$ & $\begin{array}{l}\text { LOQ }[\mu \mathrm{g} \mathrm{V} \\
\left.\mathrm{L}^{-1}\right]\end{array}$ & $R$ & $\begin{array}{l}\text { Stability } \\
{[\%]}\end{array}$ & $\begin{array}{l}\text { Recovery } \\
{[\%]}\end{array}$ \\
\hline Vanadyl acetate & 0.04 & 0.13 & 0.9999 & 2.8 & $4.6 \pm 2.1$ \\
Amavadin & 0.05 & 0.17 & 0.9999 & 2.6 & $3.7 \pm 1.7$
\end{tabular}

the quantitative column recovery of the mushroom extracts (see below, Section 3.4.3).

\subsection{Mushroom samples}

3.4.1 Water content. The water content varied between 88 and $94 \%$ for all samples, except the bulb samples, which contained 72, 86 and 84\% water (samples A, B and C, respectively). Concentrations will be given on a wet mass basis, because the whole experiments were performed with fresh samples.

3.4.2 Total $\mathrm{V}$ and extractable $\mathrm{V}$ concentrations. In the digested SRM 1573a, we detected $90 \pm 1 \%(n=4)$ of the certified V concentration, and for the SRM 1640a, the trueness was $95 \%(n=1)$ when determining the $\mathrm{V}$ concentrations in the digested samples, and $98 \%(n=1)$ when the total extractable $\mathrm{V}$ was analyzed.

Concerning the samples of Amanita muscaria, the highest $\mathrm{V}$ concentrations, namely 38-97 $\mathrm{mg} \mathrm{kg}^{-1}$, were found in the bulb samples. In the other samples, the $\mathrm{V}$ concentrations were between 6.4 and $33 \mathrm{mg} \mathrm{kg}$. Within each mushroom, the concentrations in the stipe and gills were very similar. Slightly lower concentrations were found in the skin, and the caps had the lowest $\mathrm{V}$ concentrations among all fruit-body parts. All total $\mathrm{V}$ concentrations, along with the extractable $\mathrm{V}$ concentrations and $\mathrm{V}$ species, are listed in Table 3.

Overall, $74 \pm 12 \%$ of the total $\mathrm{V}$ was extractable with the mobile phase. The repeatability of the samples of fruit-body A was between 1 and 7\% (three replicate extractions per sample). The bulb samples had the highest extraction efficiencies of 81$93 \%$, while the lowest extraction efficiencies were found for the skin samples, with 50-63\%. It will be interesting to see in future studies whether an extended extraction time or higher temperature can lead to an increased extraction efficiency in Amanita muscaria samples.

3.4.3 V species. The concentrations of the detected $\mathrm{V}$ species in the fruit-body samples are given in Table 3 . The identity of amavadin was confirmed by spiking a diluted extract of gills A with a standard solution, containing $100 \mu \mathrm{g} \mathrm{V} \mathrm{L}{ }^{-1}$ of amavadin and vanadyl acetate (see chromatograms in ESI, Fig. S11 $\dagger$ ). The data showed quantitative column recoveries (sum of all detected $\mathrm{V}$ species divided by the extractable V), with $98 \pm 9 \%$. Amavadin accounted for $4.0-83 \mathrm{mg} \mathrm{V} \mathrm{kg}^{-1}$, which is $75-96 \%$ of the extractable $\mathrm{V}$. It was not possible to determine which peak was the $\Lambda$ - and which one the $\Delta$-isomer, and thus the earlier eluting isomer will be referred to as isomer 1 , and the later eluting one as isomer 2. The ratio of isomer 2 to isomer 1 was very constant, between 1.9 and 2.2 , in all samples except the bulbs. There, the ratio was $2.4,2.4$ and 2.3 for samples A, B and $\mathrm{C}$, respectively. Interestingly, the ratio was only $0.90 \pm 0.05$ in the synthetic standard solutions. In other words, the two isomers were present at almost equal concentrations in the synthetic amavadin, while the concentrations of isomer 2 were more than twice as high as that of isomer 1 in Amanita muscaria

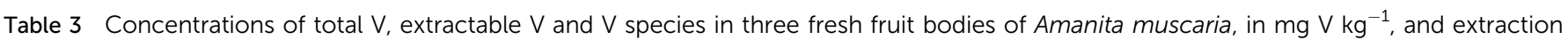
efficiencies in \% of total V. Sample A was extracted three times, whereas B and C were only extracted once.

\begin{tabular}{|c|c|c|c|c|c|c|c|}
\hline Sample & Total V & Extractable V & Extraction efficiency & Amavadin & Vanadyl acetate $^{a}$ & Unknown 1 & Other species \\
\hline Skin A & $8.5 \pm 0.6$ & $4.2 \pm 0.3$ & $49 \pm 4$ & $4.0 \pm 0.2$ & $0.0040 \pm 0.0003$ & $0.27 \pm 0.01$ & $0.32 \pm 0.03$ \\
\hline Cap A & $6.4 \pm 0.3$ & $5.1 \pm 0.3$ & $80 \pm 5$ & $4.8 \pm 0.2$ & Traces $^{b}$ & $0.32 \pm 0.03$ & $0.19 \pm 0.02$ \\
\hline Gills A & $13.5 \pm 0.3$ & $9.3 \pm 0.1$ & $69 \pm 1$ & $8.1 \pm 0.1$ & $0.0035 \pm 0.0001$ & $0.50 \pm 0.03$ & $0.20 \pm 0.01$ \\
\hline Stipe A & $16.4 \pm 2.2$ & $11.0 \pm 0.8$ & $67 \pm 5$ & $10.3 \pm 0.6$ & $0.037 \pm 0.001$ & $0.48 \pm 0.04$ & $0.28 \pm 0.09$ \\
\hline Bulb A & $38.1 \pm 0.4$ & $31.0 \pm 1.0$ & $81 \pm 3$ & $26.2 \pm 0.8$ & $0.60 \pm 0.01$ & $1.21 \pm 0.03$ & $0.59 \pm 0.13$ \\
\hline Skin B & $18.0 \pm 1.3$ & 11 & 63 & 11 & 0.0088 & 0.63 & 0.26 \\
\hline Cap B & $13.1 \pm 0.4$ & 11 & 85 & 11 & 0.0030 & 0.63 & 0.17 \\
\hline Gills B & $25.6 \pm 0.8$ & 20 & 79 & 16 & 0.0048 & 0.92 & 0.27 \\
\hline Stipe B & $25.3 \pm 0.4$ & 18 & 70 & 17 & 0.075 & 0.71 & 0.31 \\
\hline Bulb B & $58.1 \pm 1.6$ & 51 & 88 & 38 & 1.8 & 1.6 & 1.1 \\
\hline Skin C & $19.5 \pm 0.9$ & 12 & 60 & 11 & $<0.0004$ & 0.92 & 0.35 \\
\hline Cap C & $18.1 \pm 0.5$ & 13 & 73 & 12 & 0.0033 & 0.66 & 0.34 \\
\hline Gills C & $33.0 \pm 1.2$ & 23 & 71 & 22 & 0.0086 & 1.1 & 0.58 \\
\hline Stipe C & $27.5 \pm 0.7$ & 23 & 84 & 21 & 0.068 & 0.82 & 0.51 \\
\hline Bulb C & $97.4 \pm 0.7$ & 90 & 93 & 83 & 1.4 & 2.9 & 1.2 \\
\hline
\end{tabular}

${ }^{a}$ Species detected at the same retention time as the vanadyl acetate standard (vanadyl EDTA). ${ }^{b}$ Traces: between the LOD and LOQ (0.0004 and $0.0013 \mathrm{mg} \mathrm{V} \mathrm{kg}^{-1}$ ). 
extracts. Over the course of the 24 hour measurement, no interspecies conversion was observed in the re-measured standard, nor in the extracts. It is possible that naturally occurring amavadin is present in an asymmetric environment that might favor one diastereoisomer over the other.

Besides amavadin, other V-containing compounds could be detected in the extracts as well. A typical chromatogram of a bulb sample is drawn in Fig. 6, and the concentrations are given in Table 3.

The peak representing vanadyl acetate was present in most samples, but usually at low concentrations, accounting for only $0.02-0.43 \%$ of the extractable $\mathrm{V}$ except in the bulb samples, where it accounted for up to $1.8 \mathrm{mg} \mathrm{V} \mathrm{kg}^{-1}(3.4 \%$ of the extractable $\mathrm{V}$ ). As already mentioned earlier, the vanadyl moiety of vanadyl acetate was very likely complexed by EDTA. In real samples, the same will apply to any present vanadyl ions, and they will show the same retention behavior as vanadyl acetate. This was confirmed by preliminary experiments in our lab. For future investigations on environmental $\mathrm{V}$ speciation, it will be important to evaluate the behavior of small inorganic $\mathrm{V}$ species with our method systematically, but it was beyond the scope of the present study.

At around 10 minutes, another double peak can be found (Fig. 6B). It accounted for $3.1-4.4 \%$ of the extractable $\mathrm{V}$ ("unknown 1"). The highest relative concentrations were found in the skin samples, with $5.6-7.8 \%$ of the extractable $\mathrm{V}$, while it accounted for only $3.4 \pm 0.4 \%$ of the extracted $V$ in the bulb and $4.0 \pm 0.4 \%$ in the stipe samples. In gills and cap samples, between 4.6 and $6.2 \%$ of the extractable $\mathrm{V}$ was present as unknown 1 . The peak's shape was very similar to that of amavadin, albeit at a much lower concentration. The chemical structure of this compound(s) is unknown, but it can be speculated that it is related to amavadin, for example a precursor or homologue, and is also present in two isomeric forms. The ratio of the second to the first peak in bulb and stipe samples is a little lower than in the case of amavadin, namely 1.6-2.1. In the cap, gills and skin samples, however, the ratio is between 2.2 and 2.6.

During the measurement of the first samples, it was observed that the extracts also contain $\mathrm{V}$ species that are retained much longer on the column than amavadin. Therefore, replicate 1 of each part of fruit-body A was injected again and monitored for 60 minutes instead of 20 . The whole chromatogram of the bulb sample is shown in Fig. 6C, and the other chromatograms can be found in ESI, Fig. S11. $\dagger$ In all parts of Amanita muscaria, we detected one to two peaks between around 20 and 30 minutes ("unknown 2 and 3"). They only accounted for around $0.15 \%$ of the extracted $V$ in the skin, cap and gills, but were more abundant in the stipe $(1.8 \%$ of the extracted V) and bulb (5.7\%), where also two more small peaks appeared at around 20 and 30 minutes, respectively. Finally, at 52 minutes, a small peak could be found in all five chromatograms. The compound's $\mathrm{V}$ concentration was very low, only $0.01-0.13 \%$ of the extracted $V$, but it would still be interesting to explore the identity of this extremely strong retained species in the future.
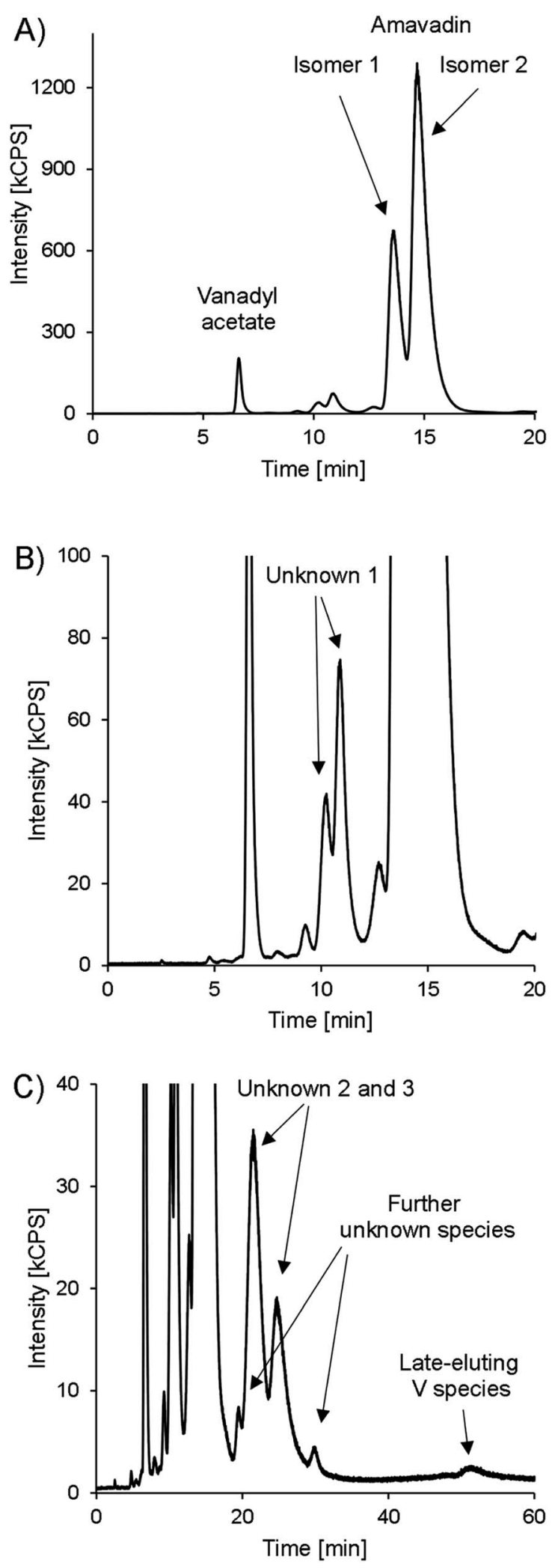

Fig. 6 HPLC-ICPMS chromatogram of $V(m / z 51)$ in bulb A, presented in different variants. (A) 0-20 minutes. (B) 0-20 minutes, zoomed in to see lower abundant species. (C) 0-60 minutes, zoomed in. 


\section{Conclusion and outlook}

We synthesized amavadin and developed a sensitive anionexchange HPLC-ICPMS method for the separation and detection of amavadin and its two diastereoisomers with a limit of quantification of $0.17 \mu \mathrm{g} \mathrm{V} \mathrm{L}{ }^{-1}$.

We applied the method on the extracts of fruit-body samples of Amanita muscaria. $75-96 \%$ of the extracted V was found in the form of amavadin. We also found other $V$ species in the extracts, of which one was eluting with a similar double-peak profile to the two diastereoisomers of amavadin. Additionally, long retained $\mathrm{V}$ containing signals were detected in all the investigated parts of the mushroom (bulb, stipe, cap, skin, and gills).

Our results add valuable and unique information to our knowledge on amavadin in mushrooms. The new method allows vanadium speciation analysis at trace concentrations in mushrooms and other environmental samples.

Until now, it was assumed that only Amanita muscaria and its few closely related species contain amavadin, because of their extraordinary V concentrations. With the developed method, it can be explored whether traces of amavadin are present in other environmental samples as well. This will help in elucidating the biogeochemical pathway of $\mathrm{V}$ and its role in the environment.

\section{Conflicts of interest}

There are no conflicts to declare.

\section{Acknowledgements}

The authors want to thank Evelyn Waldhauser, Antonia Toedling and Linda Maierhofer for their support in the lab. The authors acknowledge the financial support by the University of Graz.

\section{References}

1 Agency for Toxic Substances and Disease Registry (ATSDR), Toxicological Profile for Vanadium, U.S. Department of Health and human Services, Public Health Service, Atlanta, GA, 2012.

2 D. Rehder, Vanadium in health issues, ChemTexts, 2018, 4, 20.

3 D. Rehder, The future of/for vanadium, Dalton Trans., 2013, 42, 11749-11761.

4 S. Treviño and A. Diaz, Vanadium and insulin: Partners in metabolic regulation, J. Inorg. Biochem., 2020, 208, 111094.

5 D. Rehder, The potentiality of vanadium in medicinal applications, Inorg. Chim. Acta, 2020, 504, 119445.

6 T. I. Fortoul, V. Rodriguez-Lara, A. González-Villalva, M. Rojas-Lemus, G. Cano-Gutiérrez, M. Ustarroz-Cano, L. Colín-Barenque, P. Bizarro-Nevares, I. García-Pealez, L. F. Montaño, R. S. Jimenez-Martinez, N. Lopez-Valdez, M. L. Ruiz-Guerrero, N. A. Meléndez-García, F. A. GarcíaIbarra, V. Martínez-Baez, D. Z. Alfaro, A. Muñiz-RiveraCambas, L. S. López-Zepeda, E. M. Quezada-Maldonado and S. Cervantes-Yépez, Inhalation of vanadium pentoxide and its toxic effects in a mouse model, Inorg. Chim. Acta, 2014, 420, 8-15.

7 F. L. Assem and L. S. Levy, A review of current toxicological concerns on vanadium pentoxide and other vanadium compounds: Gaps in knowledge and directions for future research, J. Toxicol. Environ. Health, Part B, 2009, 12, 289306.

8 K. Gruzewska, A. Michno, T. Pawelczyk and H. Bielarczyk, Essentiality and toxicity of vanadium supplements in health and pathology, J. Physiol. Pharmacol., 2014, 65, 603611.

$9 \mathrm{~J}$. P. Gustafsson, Vanadium geochemistry in the biogeosphere -speciation, solid-solution interactions, and ecotoxicity, Appl. Geochem., 2019, 102, 1-25.

10 T. Ueki, N. Yamaguchi, Romaidi, Y. Isago and H. Tanahashi, Vanadium accumulation in ascidians: A system overview, Coord. Chem. Rev., 2015, 301-302, 300-308.

11 J. Costa Pessoa, E. Garribba, M. F. A. Santos and T. SantosSilva, Vanadium and proteins: Uptake, transport, structure, activity and function, Coord. Chem. Rev., 2015, 301-302, 49-86.

12 D. Rehder, The role of vanadium in biology, Metallomics, 2015, 7, 730-742.

$13 \mathrm{Z}$. Řanda and J. Kučera, Trace elements in higher fungi (mushrooms) determined by activation analysis, $J$. Radioanal. Nucl. Chem., 2004, 259, 99-107.

14 P. Kalač, Trace element contents in European species of wild growing edible mushrooms: A review for the period 20002009, Food Chem., 2010, 122, 2-15.

$15 \mathrm{~J}$. Vetter, Vanadium content of some common edible, wild mushroom species, Acta Aliment., 1999, 28, 39-48.

16 J. Falandysz, T. Kunito, R. Kubota, K. Lipka, A. Mazur, J. J. Falandysz and S. Tanabe, Selected elements in fly agaric Amanita muscaria, J. Environ. Sci. Health, Part A: Toxic/Hazard. Subst. Environ. Eng., 2007, 42, 1615-1623.

17 E. Koch, H. Kneifel and E. Bayer, Das Vorkommen von Amavadin in Pilzen der Gattung Amanita [in German], $Z$. Naturforsch., 1987, 873-878.

$18 \mathrm{~J}$. Vetter, Mineral composition of basidiomes of Amanita species, Mycol. Res., 2005, 109, 746-750.

19 H.-U. Meisch, J. A. Schmitt and W. Reinle, Schwermetalle in Höheren Pilzen, III * Vanadium und Molybdän/Heavy Metals in Higher Fungi, II I. Vanadium and Molybdenum, Z. Naturforsch., C: J. Biosci., 1978, 33, 1-6.

20 R. D. Gillard and R. J. Lancashire, Electron spin resonance of vanadium in Amanita muscaria, Phytochemistry, 1984, 23, 179-180.

21 H.-U. Meisch, W. Reinle and J. A. Schmitt, High vanadium content in mushrooms is not restricted to the fly agaric (Amanita muscaria), Sci. Nat., 1979, 66, 620-621.

22 E. Bayer and H. Kneifel, Isolation of Amavadin, a Vanadium Compound Occurring in Amanita Muscaria, Z. Naturforsch., B: Anorg. Chem., Org. Chem., Biochem., Biophys., Biol., 1972, 27, 207.

23 H. Kneifel and E. Bayer, Determination of the Structure of the Vanadium Compound, Amavadin, from Fly Agaric, Angew. Chem., Int. Ed., 1973, 12, 508. 
24 C. D. Garner, E. M. Armstrong, R. E. Berry, R. L. Beddoes, D. Collison, J. J. A. Cooney, S. N. Ertok and M. Helliwell, Investigations of Amavadin, J. Inorg. Biochem., 2000, 80, $17-20$.

25 J. A. L. da Silva, F. da Silva, J. R. João and A. J. L. Pombeiro, Amavadin, a vanadium natural complex: Its role and applications, Coord. Chem. Rev., 2013, 257, 2388-2400.

26 F. J. J. R. da Silva, Vanadium in biology-the case of the Amanita toadstools, Chem. Speciation Bioavailability, 1989, 1, 139-150.

27 P. Krauß, E. Bayer and H. Kneifei, ElektronenspinresonanzUntersuchungen an Amavadin, einem vanadiumhaltigen Naturstoff/Electron Spin Resonance Investigations of Amavadin, a Natural Product Containing Vanadium, $Z$. Naturforsch., B: Anorg. Chem., Org. Chem., 1984, 39, 829-832.

$28 \mathrm{H}$. Kneifel and E. Bayer, Stereochemistry and total synthesis of amavadin, the naturally occurring vanadium compound of Amanita muscaria, J. Am. Chem. Soc., 1986, 108, 3075-3077.

29 E. Bayer, E. Koch and G. Anderegg, Amavadin, an Example for Selective Binding of Vanadium in Nature: Studies of Its Complexation Chemistry and a New Structural Proposal, Angew. Chem., Int. Ed. Engl., 1987, 26, 545-546.

30 E. M. Armstrong, R. L. Beddoes, L. J. Calviou, J. M. Charnock, D. Collison, N. Ertok, J. H. Naismith and C. D. Garner, The Chemical Nature of Amavadin, J. Am. Chem. Soc., 1993, 115, 807-808.

31 E. M. Armstrong, D. Collison, N. Ertok and C. D. Garner, NMR studies on natural and synthetic Amavadin, Talanta, 2000, 53, 75-87.

32 T. Hubregtse, E. Neeleman, T. Maschmeyer, R. A. Sheldon, U. Hanefeld and I. W. C. E. Arends, The first enantioselective synthesis of the amavadin ligand and its complexation to vanadium, J. Inorg. Biochem., 2005, 99, 1264-1267.

33 T. Hubregtse, H. Kooijman, A. L. Spek, T. Maschmeyer, R. A. Sheldon, I. W. C. E. Arends and U. Hanefeld, Study on the isomerism in meso-amavadin and an amavadin analogue, J. Inorg. Biochem., 2007, 101, 900-908.

34 C. M. M. Matoso, A. J. L. Pombeiro, J. J. R. F. da Silva, M. F. C. G. da Silva, J. A. L. da Silva, J. L. Baptista-Ferreira and F. Pinho-Almeida, in Vanadium Compounds, ed. A. S. Tracey and D. C. Crans, American Chemical Society, Washington, DC, 1998, vol. 711, pp. 241-247.

35 M. Domarus, M. L. Kuznetsov, J. Marçalo, A. J. L. Pombeiro and J. A. L. da Silva, Amavadin and Homologues as Mediators of Water Oxidation, Angew. Chem., Int. Ed., 2016, 55, 1489-1492.

36 V. Ugone, D. Sanna, G. Sciortino, D. C. Crans and E. Garribba, ESI-MS Study of the Interaction of Potential Oxidovanadium(IV) Drugs and Amavadin with Model Proteins, Inorg. Chem., 2020, 59, 9739-9755.

37 J.-H. Huang, F. Huang, L. Evans and S. Glasauer, Vanadium: Global (bio)geochemistry, Chem. Geol., 2015, 417, 68-89.

38 K. Pyrzyńska and T. Wierbicki, Determination of vanadium species in environmental samples, Talanta, 2004, 64, 823829.
39 G. P. Dechaine and M. R. Gray, Chemistry and Association of Vanadium Compounds in Heavy Oil and Bitumen, and Implications for Their Selective Removal, Energy Fuels, 2010, 24, 2795-2808.

40 T. Jakusch, J. Costa Pessoa and T. Kiss, The speciation of vanadium in human serum, Coord. Chem. Rev., 2011, 255, 2218-2226.

41 T. Iglesias-González, C. Sánchez-González, M. MontesBayón, J. Llopis-González and A. Sanz-Medel, Absorption, transport and insulin-mimetic properties of bis(maltolato) oxovanadium (IV) in streptozotocin-induced hyperglycemic rats by integrated mass spectrometric techniques, Anal. Bioanal. Chem., 2012, 402, 277-285.

42 K. De Cremer, M. van Hulle, C. Chéry, R. Cornelis, K. Strijckmans, R. Dams, N. Lameire and R. Vanholder, Fractionation of vanadium complexes in serum, packed cells and tissues of Wistar rats by means of gel filtration and anion-exchange chromatography, J. Biol. Inorg Chem., 2002, 7, 884-890.

43 V. Nischwitz, J. T. Davies, D. Marshall, M. González, J. L. Gómez Ariza and H. Goenaga-Infante, Speciation studies of vanadium in human liver (HepG2) cells after in vitro exposure to bis(maltolato)oxovanadium(Iv) using HPLC online with elemental and molecular mass spectrometry, Metallomics, 2013, 5, 1685.

44 N. Kilibarda, S. E. Afton, J. M. Harrington, F. Yan and K. E. Levine, Rapid speciation and determination of vanadium compounds using ion-pair reversed-phase ultrahigh-performance liquid chromatography inductively coupled plasma-sector field mass spectrometry, $J$. Chromatogr. A, 2013, 1304, 121-126.

45 X. S. Li and X. C. Le, Speciation of vanadium in oils and coke and bacterial culture by high performance liquid chromatography inductively coupled plasma mass spectrometry, Anal. Chim. Acta, 2007, 602, 17-22.

46 T. V. Komarova, O. N. Obrezkov and O. A. Shpigun, Ion chromatographic behaviour of anionic EDTA complexes of vanadiurn(IV) and vanadium(V), Anal. Chim. Acta, 1991, 254, 61-63.

47 L. Minelli, E. Veschetti, S. Giammanco, G. Mancini and M. Ottaviani, Vanadium in Italian waters: monitoring and speciation of V(IV) and V(V), Microchem. J., 2000, 67, 83-90.

48 F. Aureli, S. Ciardullo, M. Pagano, A. Raggi and F. Cubadda, Speciation of vanadium(Iv) and (v) in mineral water by anion exchange liquid chromatography-inductively coupled plasma mass spectrometry after EDTA complexation, $J$. Anal. At. Spectrom., 2008, 23, 1009-1016.

49 M. A. Larsson, M. D'Amato, F. Cubadda, A. Raggi, I. Öborn, D. B. Kleja and J. P. Gustafsson, Long-term fate and transformations of vanadium in a pine forest soil with added converter lime, Geoderma, 2015, 259-260, 271-278.

50 M. Colina, P. H. E. Gardiner, Z. Rivas and F. Troncone, Determination of vanadium species in sediment, mussel and fish muscle tissue samples by liquid chromatographyinductively coupled plasma-mass spectrometry, Anal. Chim. Acta, 2005, 538, 107-115. 
51 Z. L. Chen and G. Owens, Trends in speciation analysis of vanadium in environmental samples and biological fluids-A review, Anal. Chim. Acta, 2008, 607, 1-14.

52 Z. Chen and R. Naidu, On-column complexation and simultaneous separation of vanadium(IV) and vanadium(V) by capillary electrophoresis with direct UV detection, Anal. Bioanal. Chem., 2002, 374, 520-525.

53 K. Pyrzyńska and T. Wierzbicki, Solid-phase extraction for preconcentration and separation of vanadium species in natural waters, Microchim. Acta, 2004, 147, 59-64.

54 J.-Y. Yang and Y. Tang, Accumulation and Biotransformation of Vanadium in Opuntia microdasys, Bull. Environ. Contam. Toxicol., 2015, 94, 448-452.

55 D. Wang and S. A. Sañudo-Wilhelmy, Development of an analytical protocol for the determination of $\mathrm{V}(\mathrm{IV})$ and $\mathrm{V}(\mathrm{V})$ in seawater: Application to coastal environments, Mar. Chem., 2008, 112, 72-80.

56 M. Žižić, T. Dučić, D. Grolimund, D. Bajuk-Bogdanović, M. Nikolic, M. Stanić, S. Križak and J. Zakrzewska, X-ray absorption near-edge structure micro-spectroscopy study of vanadium speciation in Phycomyces blakesleeanus mycelium, Anal. Bioanal. Chem., 2015, 407, 7487-7496.
57 P. Frank, K. Kustin, W. E. Robinson, L. Linebaugh and K. O. Hodgson, Nature and Ligation of Vanadium within Whole Blood Cells and Henze Solution from the Tunicate Ascidia ceratodes, As Investigated by Using X-ray Absorption Spectroscopy, Inorg. Chem., 1995, 34, 5942-5949.

58 M. Jensen-Fontaine, W. P. Norwood, M. Brown, D. G. Dixon and X. C. Le, Uptake and Speciation of Vanadium in the Benthic Invertebrate Hyalella azteca, Environ. Sci. Technol., 2014, 48, 731-738.

59 V. T. Kütter, M. Montes-Bayón, S. M. Sella, A. Sanz-Medel and E. V. Silva-Filho, Vanadium-binding protein in marine plankton from tropical south atlantic ocean, J. Braz. Chem. Soc., 2014, 25, 1116-1123.

60 D. C. Crans, J. J. Smee, E. Gaidamauskas and L. Yang, The Chemistry and Biochemistry of Vanadium and the Biological Activities Exerted by Vanadium Compounds, Chem. Rev., 2004, 104, 849-902.

61 A. M. N. Silva, X. Kong and R. C. Hider, Determination of the $\mathrm{p} K_{\mathrm{a}}$ value of the hydroxyl group in the $\alpha$-hydroxycarboxylates citrate, malate and lactate by ${ }^{13} \mathrm{C}$ NMR: implications for metal coordination in biological systems, BioMetals, 2009, 22, 771-778. 